\title{
Comparison of Tooth Color Change After Bleaching With Conventional and Different Light-Activated Methods
}

\author{
Sima Shahabi ${ }^{1,2}$, Hadi Assadian ${ }^{3}$, Alireza Mahmoudi Nahavandi ${ }^{4}$, Hanieh Nokhbatolfoghahaei ${ }^{*}$ \\ ${ }^{1}$ Laser Research Center of Dentistry (LRCD), Dental Materials Department, School of Dentistry, Tehran University of Medical \\ Sciences, Tehran, Iran \\ 'Iranian Dental Biomaterials Association (IDBMA), Tehran, Iran \\ ${ }^{3}$ Department of Endodontics, School of Dentistry, Shahed University, Tehran, Iran \\ ${ }^{4}$ Color Imaging and Color Image Processing Department, Institute for Color Science and Technology (ICST), Tehran, Iran \\ ${ }^{5}$ Dental Research Center, Research Institute of Dental Sciences, Shahid Beheshti University of Medical Sciences, Tehran, Iran
}

\author{
*Correspondence to \\ Hanieh Nokhbatolfoghahaei, \\ Dental Research Center, \\ Research Institute of Dental \\ Sciences, Shahid Beheshti \\ University of Medical Sciences, \\ Tehran. Iran. \\ Tel: +982122427752 ; \\ Fax: +982122427752 \\ Email: \\ Hanieh.nokhbe@gmail.com
}

Published online 26 December 2017

\begin{abstract}
Introduction: The demand for esthetic dental treatments is increasing in recent years mainly due to improved oral hygiene and better maintenance of oral health and teeth in older individuals. Bleaching of discolored anterior teeth is the most popular among esthetic dental treatments. Even individuals with sound teeth and adequate esthetics seek to have whiter teeth in the anterior region. The aim of this study was to evaluate tooth color changes following conventional in-office bleaching techniques compared to light-activated methods using different light sources.

Methods: Seventy sound anterior teeth (devoided of caries and/or fracture), extracted for periodontal and orthodontic reasons were selected and allocated to 7 groups: (A) control, (B) conventional bleaching (C) LED-activated bleaching, (D) KTP laser-activated bleaching, (E) diode laseractivated bleaching, (F) Nd:YAG laser-activated bleaching and (G) CO2 laser-activated bleaching. Colorimetric evaluation was carried out before and after treatment using a spectrophotoradiometer. Data were analyzed by one- and two-way analysis of variance (ANOVA) as well as multiple comparison methods.

Results: The results showed that all bleaching procedures were effective in reducing the yellowness index. However, the KTP laser-activated bleaching was significantly more effective than the other techniques in 95\% confidence level. It was also seen that CO2 laser activated method has outperformed groups E, F and G and the conventional bleaching without light activation was not effective at all and represented similar results with the control group. Furthermore, the groups $\mathrm{E}$ and $\mathrm{G}$ had almost the same results in decreasing the yellowness index.

Conclusion: The results showed that all bleaching techniques were effective however, the KTP laser-activated bleaching was significantly more efficient, closely followed by the CO2 laseractivated bleaching technique.

Keywords: Laser bleaching; Tooth color change; Spectroradiometer.
\end{abstract}

\section{Introduction}

A beautiful smile plays a pivotal role in social interactions, furthermore, a large number of people are influenced by mass media to seek an effective, enduring and effortless treatment plan. ${ }^{1}$ Bleaching techniques can be a conservative method to provide patients with a beautiful smile $^{2-4}$ when compared to other techniques such as laminate veneers, composite facings or full-coverage restorations.

Tooth color is determined by different chromatic characteristics of enamel, dentin and pulp. ${ }^{4,5}$ However, tooth discolorations vary in etiology, appearance, location, severity, and are dependent on tooth structure. Such discolorations are classified as internal and external. External tooth discolorations can be removed by prophylactic procedures, but treating internal discolorations requires chemical bleaching techniques. ${ }^{4}$ Today, various tooth whitening agents with different concentrations are commercially available, like $3 \%$ to $38 \%$ hydrogen peroxide (HP), $10 \%$ to $30 \%$ carbamide peroxide or a mixture of sodium peroxide and HP. ${ }^{6}$

$\mathrm{HP}$ is the major component and chemical activator of bleaching agents by virtue of its reactional chemistry, particularly with organic chains of stains and pigments.

Please cite this article as follows: Shahabi S, Assadian H, Mahmoudi Nahavandi A, Nokhbatolfoghahaei H. Comparison of tooth color change after bleaching with conventional and different light-activated methods. J Lasers Med Sci. 2018;9(1):27-31. doi:10.15171/ jlms.2018.07. 
HP can be used in its pure form or as the breakdown product of other bleaching agents such as sodium perborate and carbamide peroxide. ${ }^{7}$

One of the most accepted theories on the mechanism of action of bleaching agents is that free radicals liberated from HP attack organic molecules and sets them into a stable condition. This causes other free radicals to react with unsaturated chemical bonds and alter their electron arrangement and therefore transform the energy absorption of organic molecules, this is the underlying process which is seen in enamel. These changes in energy absorption create simpler molecules that reflect less light and therefore makes enamel appear brighter. ${ }^{8}$

Usually in-office, home bleaching or over the counter (OTC) products are used for bleaching of vital teeth. ${ }^{9}$ Inoffice bleaching uses high-concentration HP (i.e., 15\%$40 \%)$ that can be activated by light or heat. This method is suitable for patients with severe discolorations or even a single discolored tooth in the arch. It also can be beneficial for uncooperative patients. ${ }^{4,10}$

Different light sources can be used to activate bleaching agents such as halogen, plasma arc lamp, LED, and lasers (argon, diode, KTP, Nd:YAG, $\mathrm{CO}_{2}$, etc) or a combination. ${ }^{11-14}$ Various studies have shown different tooth color changes following bleaching. Kiomars et al evaluated 2 different wavelengths of diode laser $(\lambda=810$ $\mathrm{nm}$ and $\lambda=980 \mathrm{~nm}$ ) for teeth color changes. They concluded that there was no statistical difference between the 2 laser bleached groups. ${ }^{15}$

The aim of this study was to evaluate tooth color changes, following conventional and light-activated in-office bleaching techniques, by different light sources, using a spectrophotoradiometer.

\section{Methods}

The study was carried out in an experimental in vitro design.

\section{Sample Preparation}

Seventy sound anterior teeth (devoided of caries and/ or fracture) which had been extracted for periodontal and orthodontic reasons were selected. The teeth were cleansed by ProphyPaste (Prophylaxis, Golchadent, Iran) using a brush slow-speed hand-piece. Thereafter, all samples were immersed in Chloramine $\mathrm{T}$ for 1 week and stored in distilled water at room temperature $\left(25^{\circ} \mathrm{C}\right)$ before the experiment. The color of each sample was assessed by VITA Easyshade Compact (Vident, USA) before random allocation to the groups. The teeth were mounted in a self-cure transparent acrylic resin (TR.II. Acropars, Iran) with a background of $\mathrm{TiO} 2$ (the whitest material). This was done to create a peripheral environment which is as neutral and achromatic as possible. Each sample was marked in its upper, middle and lower third for further evaluations.

Spectrophotoradiometer was used to evaluate tooth color changes following different office bleaching techniques. The bleaching techniques included (A) no treatment, (B) bleaching without light-activation (conventional) (C) LED-activated bleaching, (D) KTP laser-activated bleaching, (E) Diode laser-activated bleaching, (F) Nd:YAG laser-activated bleaching and $(\mathrm{G}) \mathrm{CO}_{2}$ laseractivated bleaching.

\section{Bleaching of the Samples}

The bleaching agent used in all experimental groups was Xtra Boost 40\% (Opalescence, USA). In all experimental groups, (except for the control, i.e., group A), the base and activator were mixed and then a $2 \mathrm{~mm}$-thick piece of the resultant red gel was applied on each tooth. In group B (conventional technique), the gel was washed away after 20 minutes. The process was repeated 2 more times with 1-minute rest intervals. Then the teeth were dried. In other groups, different (LED, KTP laser, diode laser, Nd:YAG laser, CO2 laser) lasers were applied for 30 seconds. This procedure was also repeated 3 more times with 1-minute rest intervals. Then, following a 3-minute rest time, the gel was removed and the sample rinsed. LED activation (group C) of the bleaching agent was done at a distance of 5-6 $\mathrm{mm}$ between the bleaching handpiece and the sample so that the light would cover the whole tooth surface. Group D was exposed to KTP laser $(\lambda=532$ nm) (Starline, Lambda Physik, Germany) under the following parameters: energy $=4 \mathrm{~mJ}$, pulse width $=20 \mathrm{~ns}$, power $=4 / 20=0.2 \times 106 \mathrm{~W}$, repetition rate $=10 \mathrm{~Hz}$, beam diameter $=1.5 \mathrm{~mm}$. In group $\mathrm{E}$, the bleaching gel was activated by diode laser $(810 \mathrm{~nm})$ (Gigaa laser, China) using a Biostimulation handpiece, at a power of $1.5 \mathrm{~W}$ in continuous wave (CW) at a distance of 5-6 mm between handpiece and the tooth so that the laser light would cover the whole tooth surface. In group $\mathrm{F}$, the bleaching agent was activated by Q-Switched Nd:YAG laser $(\lambda=1064 \mathrm{~nm})$ (Fotona, Slovenia, EU) using the following parameters: repetition rate $=20 \mathrm{~Hz}$, pulse width $=20 \mathrm{~ns}$, energy $=100$ $\mathrm{mJ}$, beam diameter $=3 \mathrm{~mm}$, pulse power $=\mathrm{E} / \zeta=(100$ $\mathrm{mJ} / 20 \mathrm{~ns})=50 \mathrm{~mW}$. In group $\mathrm{G}$, activation of the bleaching gel was done by the $\mathrm{CO}_{2}$ laser $(\lambda=10600 \mathrm{~nm}$, Deka, Italy), using the following parameters: power $=0.6 \mathrm{~W}$, repetition rate $=20 \mathrm{~Hz}$, level 3 (current pulse length $=1.5 \mathrm{~ms}$ ) at a distance of 1-2 $\mathrm{mm}$ between handpiece and the tooth so that the laser light would cover the whole tooth surface.

\section{Colorimetry}

The devices used for the colorimetric procedure included:

- A spectrophotoradiometer (Konica Minolta CS2000, Japan) (wavelength range: 380-780 nm. FWHM: 5 $\mathrm{nm}$ ) was used. Light and device set ups were done according to the manufacturer's instructions.

- A rectified incandescent light source

The samples were placed in front of the spectrophotoradiometer (common name is spectroradiometer). The light source was placed at a 
45-degree angle with respect to the axis perpendicular to the sample surface, whereas the spectroradiometer was placed at a zero-degree angle with respect to the axis perpendicular to the sample surface and at approximately $70 \mathrm{~cm}$ distance. These arrangements simulate $45^{\circ} / 0^{\circ}$ geometry. ${ }^{16}$ The viewing angle of the device was set at 0.1 degrees. This viewing angle resulted in an area of measurement of about $0.8 \mathrm{~mm}$ in diameter at the middle of the samples. To avoid reproducibility errors, measurements were repeated 3 times for each sample and the mean was used for further analyses.

The samples were evaluated in three zones of cervical, middle and incisal before and after bleaching. Viewing condition used for the colorimetric evaluation was (D65/20) according to the corresponding and pertinent literatures. ${ }^{17,18}$ The yellowness and whiteness indices were calculated according to ASTM E313-10 standard. ${ }^{19}$ Viewing conditions were set to $\mathrm{D} 65 / 2^{0}$ for calculation of indices. Data were statistically analyzed by two-way analysis of variance (ANOVA) as well as post hoc ANOVA test.

\section{Results}

Since the ASTM E313 whiteness formula scope is for samples with whiteness numbers within the range $40<$ $\mathrm{WI}<(5 \mathrm{Y}-280)$ and the calculated values do not meet such requirements, two-way ANOVA test was used to evaluate the values of yellowness index differences. H0 (the null hypothesis) is "different bleaching techniques and different locations of teeth have quite the same results" and consequently $\mathrm{H} 1$ would be all possible conditions except as defined in H0. A sufficiently small $P$ value for both factors in the two-way ANOVA suggests significant difference between different levels of factors.

The more negative the yellowness index difference, the more influential the bleaching process. As yellowness index difference is studied under the 2 factors, namely, region of tooth (the cervical, the middle and the incisal) and Laser type, a two-way ANOVA test has been applied to the test. Results have been illustrated in Table 1 .

The values shown in the right column in Table 1 show the significance of the test. Using two-way ANOVA test, it has been observed that different laser bleaching techniques show different bleaching capabilities $(P=0)$.

Results also showed an insignificant effect of treatments on the different part of tooth $(P=0.2507)$. It has also been observed that there is no interaction between the 2

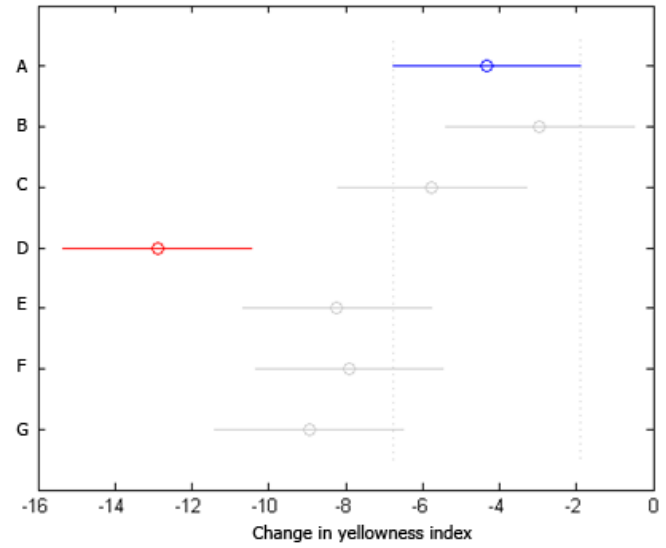

Figure 1. Post Hoc ANOVA Test.

studied factors $(P=0.5384)$.

Post hoc ANOVA test has been applied to the data. multcompare command in MATLAB programming software carries out multiple comparisons between laser types.

Post hoc ANOVA test results have been depicted in Figure 1. This plot could be used for the comparison of all 7 laser types that have been used in this study. Comparison has been done for the group "A" (shown in blue) as an example. It could be seen that, in the studied significance level, just the laser type KTP treatment (shown in red) has been better in decreasing yellowness index than control group (group A), though no significant statement could be made for other bleaching techniques (groups).

The results showed that all bleaching procedures were effective in reducing the yellowness index. However, the KTP laser-activated bleaching was significantly more effective than other techniques in 95\% confidence level as compared to control group. It can also be seen that KTP laser activated method has outperformed groups of E, F and G. However this improvement is insignificant. The statistical analyses showed that conventional bleaching without light activation was not effective at all and represented similar results with the control group. It could also be seen that the groups E, and G have almost the same results with regard to decreasing the yellowness index.

\section{Discussion}

Various methods have been proposed to evaluate tooth color changes following bleaching techniques. These

Table 1. The results of Two-Way ANOVA Test to Evaluate the Combined Effect of Bleaching and Different Tooth Parts

\begin{tabular}{llllll}
\hline Source & Sum of Squares & $\boldsymbol{d f}$ & Mean Square & F & Probe $>$ F \\
\hline Columns & 1958.8 & 6 & 326.468 & 7.93 & 0 \\
Rows & 475.6 & 9 & 52.841 & 3.28 & 0.2507 \\
Interaction & 2157.4 & 54 & 39.953 & & 0.5384 \\
Error & 5761.4 & 140 & 41.153 & & \\
Total & 10353.2 & 209 & & & \\
\hline
\end{tabular}


methods are categorized into subjective, including visual analysis according to a standard shade guide, and objective methods such as using a spectrophotometer, ${ }^{20}$ colorimeter and software analysis. ${ }^{21}$ Visual methods lack adequate accuracy. ${ }^{21}$ While using colorimeters and spectrophotometers have limitations related to the light beams evaluating the borders of the aperture penetrating into the semitransparent bed of the tooth, (due mainly to the nature of the tooth structure) thereby resulting in underestimation of the reflected light by the system. ${ }^{22}$ In various studies where subjective and objective methods were used in vivo, although the area of discoloration was limited, the influence of the dark background of the oral cavity behind the tooth (which is a translucent object) and the pink color of the gingiva in the vicinity of the cervical area of the tooth of interest could not be overlooked. Hence, in order to avoid such interactions in the current investigation, extracted teeth were mounted in $\mathrm{TiO} 2$ incorporated acrylic resins to equalize the environmental contrast in all samples.

Since the tooth color is determined by a combination of optical properties of enamel, dentin and pulp, and on the other hand it is influenced by the percentage of these structures in different regions of each tooth, each sample was divided into 3 parts for separate and independent chromatic analysis.

It is demonstrated in the relevant literature that the most common bleaching technique used in dental offices is chemical (conventional) followed by LED activated techniques. This was the reason why these 2 techniques were taken into account in this study to be compared with laser-assisted methods.

Although it is claimed by the manufacturer and is supported by another study ${ }^{4}$ that Xtra Boost bleaching material does not require external energy source for activation, some authors believe that external energy sources improve whitening efficiency of the bleaching material. ${ }^{12,13}$

Effectiveness of different lasers in tooth whitening has extensively been investigated worldwide. However, it is not possible to compare these results, due to the diversity of the consequent results, lack of equality in irradiation parameters and selected samples, as well as differences in research methodology and evaluations. In the current investigation, all energy sources were equalized on the samples and were applied under similar conditions. Also all samples were assessed by a single evaluation technique and data analysis which makes it possible to compare different lasers with each other as well as visible LED light and conventional method. Each parameter used in this investigation was employed according to the best previous results. In a study by Wetter et $\mathrm{al}^{23}$ in 2004 , the bleaching efficacy of LED was compared with diode laser while using Xtra Boost. In all parameters, the laser group outperformed the other modalities used in comparison except for luminosity, which concurs with the results of our investigation.

In the current study, $\mathrm{CO} 2$ provided acceptable bleaching results. It should be remembered that (as stated by Luk et $\mathrm{al}^{24}$ in 2004) temperature rise following CO2 laser application can have deleterious effects on the dental pulp. Therefore, such treatment is not recommended in vivo. In this study, the best tooth whitening results were obtained by KTP laser which was in accordance with the study by Kuzekanani and Walsh in 2009. ${ }^{25}$ Correspondingly, the results of our investigation were in accordance with Fornaini et $\mathrm{al}^{1}$ in 2013, who compared KTP and diode lasers in terms of tooth color changes and the resultant temperature rise. Also, in another 2007 study by Zhang et $\mathrm{al}^{26}$ pulpal temperature changes were compared following use of diode and KTP lasers in comparison with LED light using HP. The authors revealed that LED and diode laser imposed minimal and maximal temperature increments, respectively. In light of the minimal temperature increase on using the KTP laser as compared to the diode laser (as confirmed by Fornaini et $\mathrm{al}^{1}$ and Zhang et $\mathrm{al}^{26}$ ), moreover, the presence of such temperature changes being within the scope of reversible pulpal inflammatory reactions, it can be stated that KTP laser can provide more acceptable results with less hazards to the dental pulp in comparison with other lasers.

Strobl et $\mathrm{al}^{27}$ in 2010 used a hand-made bleaching gel containing 35\% HP and concluded that laser intervention in the bleaching process did not necessarily provide more successful clinical results in comparison with conventional methods. In contrast, our study showed that the conventional technique did not show any difference with the group in which no intervention was contemplated in terms of tooth color change. On the other hand, Nd:YAG laser group resulted in whiter teeth, which although was not statistically significant. In that study, VITA color scale and dental chromometer ShadeEye NCC were used to evaluate tooth color changes. However, in the current study, tooth color changes were recorded spectrophotometrically. This technique can be more reliable like in the in vivo study by Strobl et al. ${ }^{27}$ However, the differences in the results of the 2 studies mentioned can be attributed to the minute differences in the power and frequency of the devices used and the methods employed.

Marcondes et $\mathrm{al}^{28}$ in 2009 evaluated the effect of different thicknesses of HP gel when exposed to halogen light and Nd:YAG laser. In this study, VITA color scale was used to evaluate color changes. The results showed similar bleaching effects of halogen light and Nd:YAG laser. The results concur with our findings that Nd:YAG laser can produce whitening effects when used in combination with HP gel.

\section{Conclusion}

Although all bleaching procedures were effective in reducing the yellowness index, activation of the bleaching 
agent by KTP laser could reduce the yellowness of the teeth at 95\% confidence level. CO2 laser-assisted bleaching could also be effective in providing whiteness albeit at a lower confidence level. However, this technique is not recommended due to the resultant increases in pulpal temperature.

\section{Conflict of Interests}

None.

\section{Ethical Considerations}

None to be declared.

\section{Acknowledgments}

This study was supported by Laser Research Center of Dentistry of Tehran University of Medical Sciences (Code number: 91-02-97-11066), Tehran, Iran.

\section{References}

1. Fornaini C, Lagori G, Merigo E, et al. Analysis of shade, temperature and hydrogen peroxide concentration during dental bleaching: in vitro study with the KTP and diode lasers. Lasers Med Sci. 2013;28(1):1-6. doi:10.1007/s10103011-1037-4

2. Burrows S. A review of the efficacy of tooth bleaching. Dent Update. 2009;36(9):537-538, 541-534, 547-538 passim.

3. Matis BA, Cochran MA, Eckert G. Review of the effectiveness of various tooth whitening systems. Oper Dent. 2009;34(2):230-235. doi:10.2341/08-74

4. Mondelli RF, Azevedo JF, Francisconi AC, Almeida CM, Ishikiriama SK. Comparative clinical study of the effectiveness of different dental bleaching methods - two year follow-up. J Appl Oral Sci. 2012;20(4):435-443.

5. Joiner A. The bleaching of teeth: a review of the literature. $J$ Dent. 2006;34(7):412-419. doi:10.1016/j.jdent.2006.02.002

6. Dostalova T, Jelinkova H, Housova D, et al. Diode laseractivated bleaching. Braz Dent J. 2004;15 Spec No:Si3-8.

7. Sulieman MA. An overview of tooth-bleaching techniques: chemistry, safety and efficacy. Periodontol 2000. 2008;48:148-169. doi:10.1111/j.1600-0757.2008.00258.x

8. Summitt JB, Robbins JW, Hilton TJ, Schwartz RS, Dos Santos JR Jr. Fundamentals of operative dentistry: a contemporary approach. 3rd ed. Quintessence: Chicago; 2006.

9. Joiner A. Review of the effects of peroxide on enamel and dentine properties. J Dent. 2007;35(12):889-896. doi:10.1016/j.jdent.2007.09.008

10. Buchalla W, Attin T. External bleaching therapy with activation by heat, light or laser--a systematic review. Dent Mater. 2007;23(5):586-596. doi:10.1016/j. dental.2006.03.018

11. Bernardon JK, Sartori N, Ballarin A, Perdigao J, Lopes GC, Baratieri LN. Clinical performance of vital bleaching techniques. Oper Dent. 2010;35(1):3-10. doi:10.2341/09$008 \mathrm{cr}$

12. Marson FC, Sensi LG, Vieira LC, Araujo E. Clinical evaluation of in-office dental bleaching treatments with and without the use of light-activation sources. Oper Dent. 2008;33(1):15-22. doi:10.2341/07-57
13. Ontiveros JC, Paravina RD. Color change of vital teeth exposed to bleaching performed with and without supplementary light. J Dent. 2009;37(11):840-847. doi:10.1016/j.jdent.2009.06.015

14. Sulieman M, Addy M, Macdonald E, Rees JS. A safety study in vitro for the effects of an in-office bleaching system on the integrity of enamel and dentine. J Dent. 2004;32(7):581590.

15. Kiomars N, Azarpour P, Mirzaei M, Hashemi Kamangar SS, Kharazifard MJ, Chiniforush N. Evaluation of the Diode laser $(810 \mathrm{~nm}, 980 \mathrm{~nm})$ on color change of teeth after external bleaching. Laser Ther. 2016;25(4):267-272. doi:10.5978/islsm.16-OR-21

16. Linkevicius T, Vindasiute E, Puisys A, Linkeviciene L, Maslova N, Puriene A. The influence of the cementation margin position on the amount of undetected cement. A prospective clinical study. Clin Oral Implants Res. 2013;24(1):71-76. doi:10.1111/j.1600-0501.2012.02453.x

17. Dozic A, Kleverlaan CJ, El-Zohairy A, Feilzer AJ, Khashayar G. Performance of five commercially available tooth colormeasuring devices. J Prosthodont. 2007;16(2):93-100. doi:10.1111/j.1532-849X.2007.00163.x

18. Johnston WM. Color measurement in dentistry. J Dent. 2009;37 Suppl 1:e2-6. doi:10.1016/j.jdent.2009.03.011

19. Wadhwani C, Hess T, Faber T, Pineyro A, Chen CS. A descriptive study of the radiographic density of implant restorative cements. J Prosthet Dent. 2010;103(5):295-302. doi:10.1016/s0022-3913(10)60062-5

20. Braun A, Jepsen S, Krause F. Spectrophotometric and visual evaluation of vital tooth bleaching employing different carbamide peroxide concentrations. Dent Mater. 2007;23(2):165-169. doi:10.1016/j.dental.2006.01.017

21. Joiner A. Tooth colour: a review of the literature. J Dent. 2004;32 Suppl 1:3-12.

22. Bolt RA, Bosch JJ, Coops JC. Influence of window size in small-window colour measurement, particularly of teeth. Phys Med Biol. 1994;39(7):1133-1142.

23. Wetter NU, Barroso MC, Pelino JE. Dental bleaching efficacy with diode laser and LED irradiation: an in vitro study. Lasers Surg Med. 2004;35(4):254-258. doi:10.1002/ 1sm.20103

24. Luk K, Tam L, Hubert M. Effect of light energy on peroxide tooth bleaching. J Am Dent Assoc. 2004;135(2):194-201; quiz 228-199.

25. Kuzekanani M, Walsh LJ. Quantitative analysis of KTP laser photodynamic bleaching of tetracycline-discolored teeth. Photomed Laser Surg. 2009;27(3):521-525. doi:10.1089/ pho.2008.2332

26. Zhang C, Wang X, Kinoshita J, et al. Effects of KTP laser irradiation, diode laser, and LED on tooth bleaching: a comparative study. Photomed Laser Surg. 2007;25(2):91-95. doi:10.1089/pho.2006.2025

27. Strobl A, Gutknecht N, Franzen R, Hilgers RD, Lampert F, Meister J. Laser-assisted in-office bleaching using a neodymium:yttrium-aluminum-garnet laser: an in vivo study. Lasers Med Sci. 2010;25(4):503-509. doi:10.1007/ s10103-009-0675-2

28. Marcondes M, Paranhos MP, Spohr AM, et al. The influence of the Nd:YAG laser bleaching on physical and mechanical properties of the dental enamel. J Biomed Mater Res B Appl Biomater. 2009;90(1):388-395. doi:10.1002/jbm.b.31297 